published in The LANCET of April 30th? The election took place on Friday last and our candidate was successful with 3809 votes, being third of the 35 (from a list of 63 candidates) who were elected to receive the benefits of the institution. - I am, Sirs, yours faithfully,

HaROLD S. SingTON,

Secretary, St. Luke's Medical Lodge of Instruction.

St. Mary's Mansions, W., May 23rd, 1904.

\section{A SLIP.}

To the Editors of THE LANCET.

SIRS - I shall be much obliged if you will kindly insert the following statement in your next issue. In my address to the Royal College of Physicians on March 28th I inadvertently spoke of Dr. George Oliver, who has recently founded and endowed the Oliver-Sharpey lectureship at the Royal College of Physicians of London, as formerly of Harrogate, an expression which may, I am afraid, lead the Fellows of the College and others who may see my address to conclude that Dr. Oliver has left Harrogate. He informs me that he has no intention of leaving and that he will in the future, as during the last 15 years, reside and practise as a consulting physician in Harrogate during the summer months from June to October. Regretting the mistake I made and the annoyance I fear it has occasioned to our kenefactor, I am, Sirs, yours faithfully,

Belford, Northumberland, May 24th, 1934. W. S. CHURCH.

\section{SEPTIC CONJUNCTIVITIS.}

To the Editors of THE LANCET.

SiRs, - In THE LANCET of Nov. 7th, 1903, you published some clinical notes I had made on a condition I described as "septic conjunctivitis." My attention has recently been drawn to an article by Parinaud on Infective Conjunctivitis and a review thereof in the May number of the Ophthalmic Revien. The description given corresponds exactly with what I gave in my paper-constitutional disturbance, resemblance to trachoma, ptosis, non purulent discharge, affection of the preauricular glands, usually aniocular, therefore probably not very contagious, sugges. tion of animal infection, and slow complete recovery. No one reading the two accounts could doubt for a moment that the same condition was being described. The point to which I wish now to draw attention is that it is by no means so rare a condition as is suggested by the article in question which states that 20 cases only of this disease have been hitherto recorded, for even in my own practice I have had certainly over 20 cases. The explanation is that this disease is not, as I have before pointed out, differentiated in the English text-books on ophthalmology, so far as I have read, and I venture to suggest that those responsible for future editions would do well to give attention to this point. I am, Sirs, yours faithfully,

Weymouth-street, W., May 24th, $1904 . \quad$ RoBER' W. DOYNE.

\section{BURNING FROM THE X RAYS. \\ To the Editors of THE LANCET.}

SIRS, - In the recent trial of the case of Smith $v$. Pare it was stated that the burns caused by the $x$ rays are the most intractable known. In my experience at this hospital $I$ have not found it so, although at first I certainly had some difficulty in curing them. But since I have used the following ointment 1 have found them amenable enough to treatment and the dermatitis soon disappears. Formula : Plumbi oxidum, one drachm; zinci carbonas, two drachms; glycerinum, one drachm; oleum olivæ, half a drachm; adeps benzoatus, to one ounce. The ointment to be applied freely. I am, Sirs, yours faithfully,

$$
\text { H. LYLE, }
$$

May 24th, 1904

Senior Surgeon to the Liverpool Hospital for Cancer and Skin Diseases.

\section{THE OLD HARDSHIP OF LONDON MEDICAL STUDENTS.}

To the Editors of THE LANCET.

SiRs,-In reply to your correspondent "Hard Lines" in THE LANCET of May 21st, I should like to point out that, though everyone will sympathise with him in his inability to pa is ull the final subjects at one time and more especially ( $n$ account of the untoward circumstances which prevented him taking the examination at a time when he would perhaps have found it easier to do so, the position really only emphasises the greater amount of sound knowledge required for the degrees of those universities where the system of requiring all the final subjects to be passed at the same time obtains. It is comparatively easy to cram up one subject, to pass in that, and then while partially forgetting this to go on to another. It is surely most important that a man should be able to retain a good knowledge of all the final subjects and those who have shown themselves able to do so, whether from harder work, longer study, or greater ability, have a right to bave the fact recognised to some extent

May 23rd, 1904. I am, Sirs, yours faithfully,

JUSTICE TO ALI.

\section{THE GERMAN CONGRESS OF INTERNAL MEDICINE.}

(From our Berdin Correspondent.)

THE German Congress of Internal Medicine met this year at Leipsic from April 18th to 21st, Dr. MERKEL (Nurem berg) being in the chair. The official subject of discussion was

Arterio-sclerosis.

Professor MaRCHAND (Leipsic) said that arterio-sclerosis was a degenerative process, although inflammation or production of new tissue might sometimes happen. A distinction must be made between arterio-sclerosis, hypertrophy of the media, and syphilitic arteritis. Arteriosclerosis was caused by functional hyper-exertion of the vessels and by accidental general or local causes, such as general impairment of nutrition, toxic and infectious processes, heredity, and influence of temperature. A certain form of sclerosis of the aorta, especially of the media and intima, was caused by syphilis and in some cases gumma might develop in the walls of the aorta; this form was termed meso-aortitis productiva (Chiari). Superficial atheromatous degeneration of the intima of the aorta in youthful individuals must be regarded as a symptom of the process. The degeneration of the elastic elements produced a more or less diffase extension of the walls of the artery. Arterio-sclerosis was not seldom associated with hypertrophy of the left ventricle as a sequel to the general increase of resistance in the circulation. The process should be termed athero-sclerosis or sclero-atherosis of the arteries.

Professor ROMBERG (Marburg) said that the most important alteration of sclerosed arteries was the deficient elasticity which was somewhat overcome by aneurysmal dilatation of the lumen; the circulation was also hindered by the narrowing and lengthening of the sclerosed arteries. A slight hypertrophy of the left ventricle was somewhat rare and was present only in marked sclerosis of the aorta and the splanchnic arteries. With regard to the symptoms of arterio-sclerosis he said that sclerosis of the coronary arteries might produce angina pectoris and cardiac asthma ; sometimes the disease showed only the uncharacteristic symptoms of chronic cardiac failure. The kidneys were sometimes affeoted with chronic interstitial inflammation complicated by insufficiency of the hypertrophied heart. The effects produced on the nervous system included neurasthenic troubles which occurred in the primary stage and might eventually lead to insanity. Diseases of the sensory organs and of the gastro-intestinal canal were rare. The resulting disorders of the nerves of the extremities and the general vaso-motor neuroses were very interesting; intermittent claudication might be the first symptom of arterio-sclerotic gangrene. For the localisation of the disease in the different parts of the body the functional effects were important and not merely the anatomical lesions. Apart from general bodily over-fatigue substances which acted injuriously on the nervous system might cause the disease ; over indulgence in tobacco, spirits, coffee, and tea was expecially prejudicial because they produced considerable alterations in the tonicity of the blood-vessels. Arterio-sclerosis was not due to senility

I For this report we wish to tender our thanks to the editor of the Deutsche Medicinische Wochenschrift, thiough whose courtesy it has been forwarded to us by our correspondent. 